\title{
Automation of Ice Fractures and Calving Events Monitoring Using Medical Imaging Ridge Detection Algorithms
}


Constrained by local embayment and pinning points, ice shelves actively participate in the ice flow restrain by buttressing
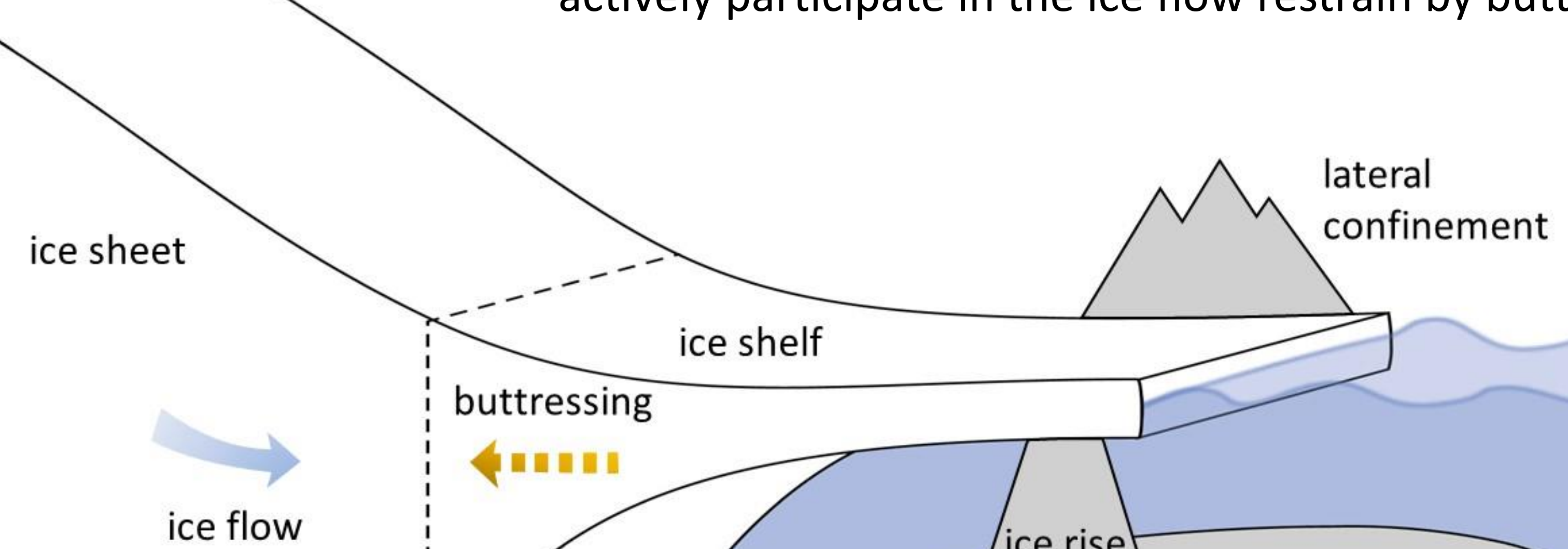

grounding line 


\section{Damage structures are participating in the destabilization}

of ice shelves and remote sensing can observe it

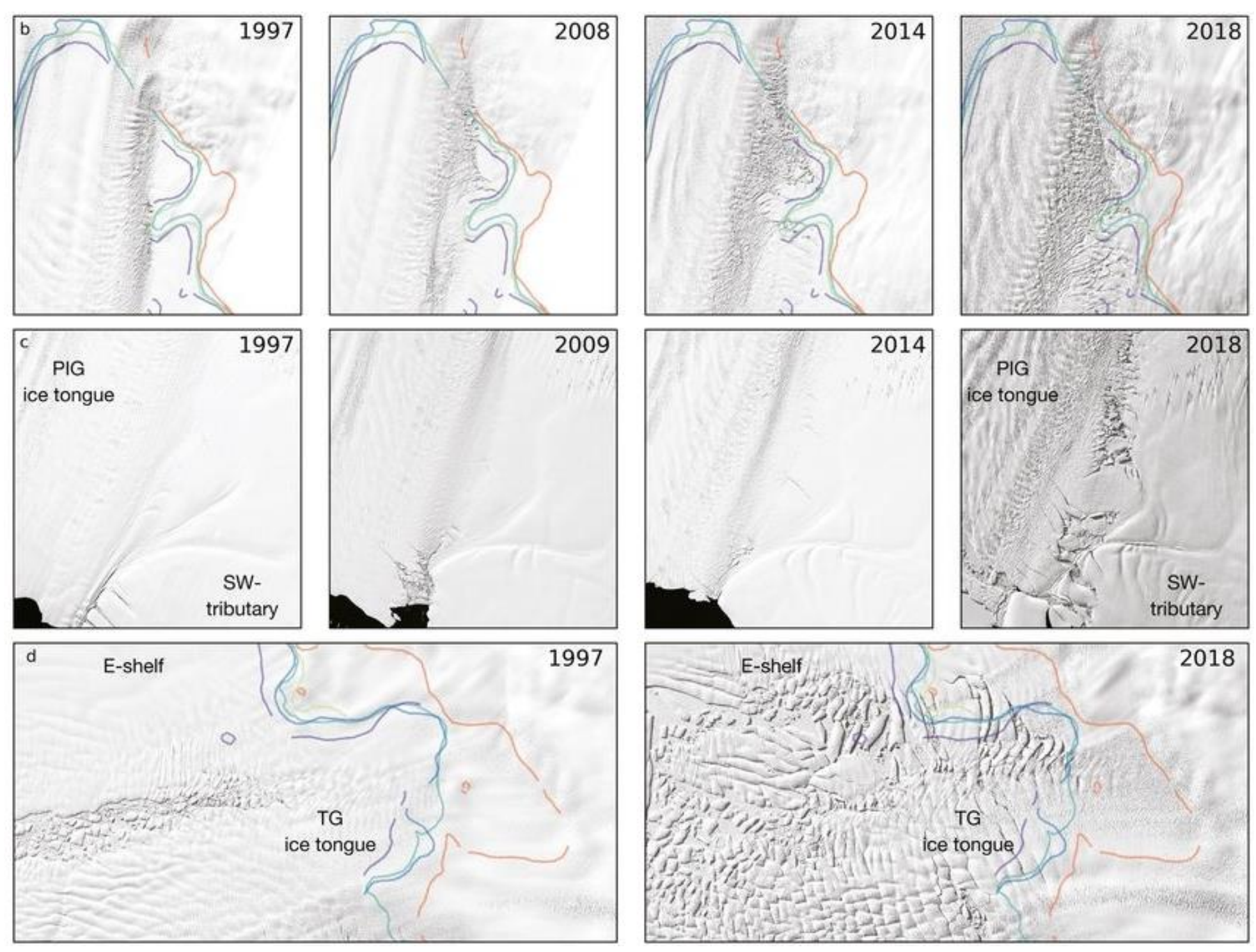


Nevertheless, damaged structures are still observed by visual inspection, while edge detection techniques are common in medical imaging

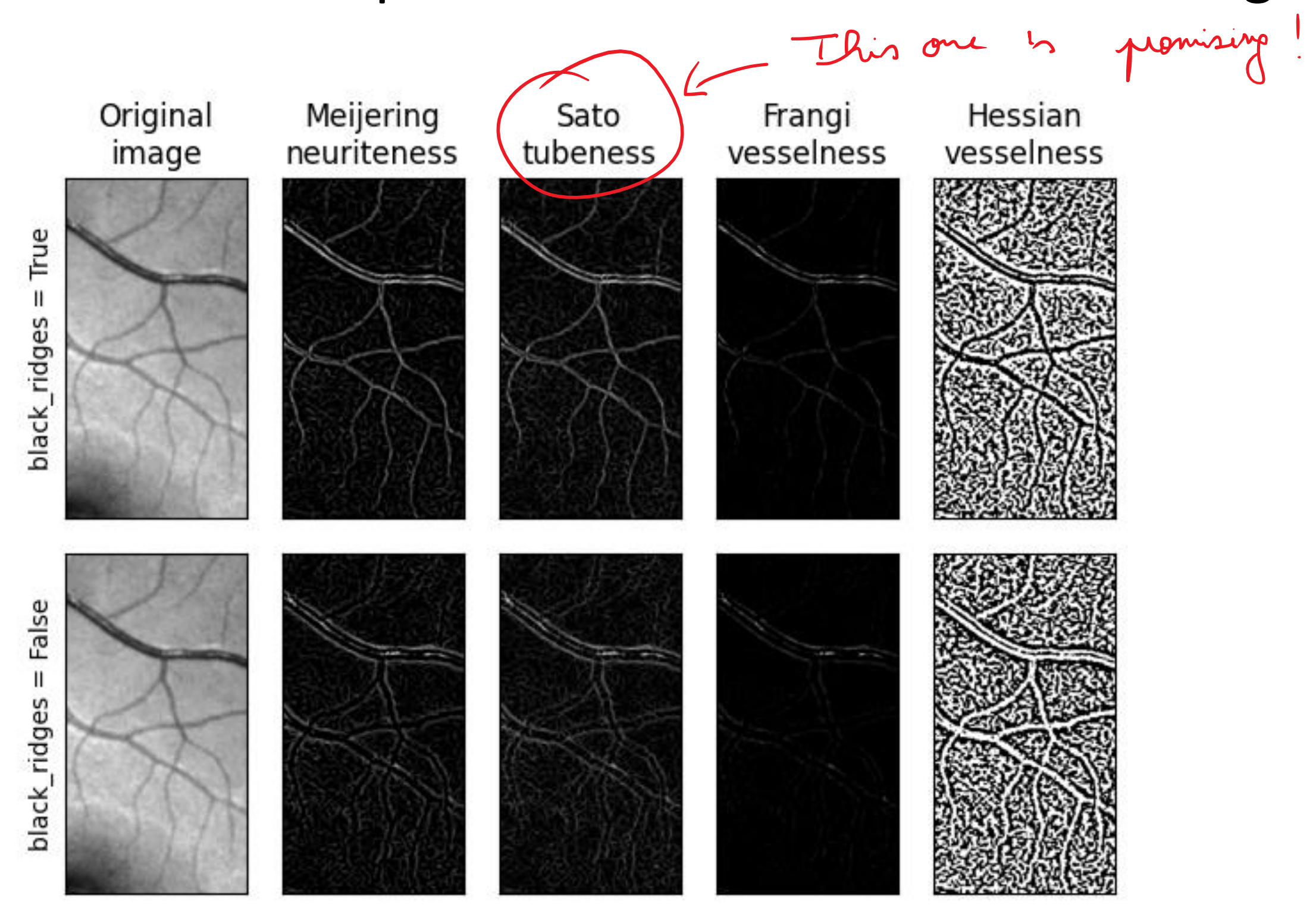




\section{Sentinel-1}

Reading

Calibration

Log Transform

Speckle Filter

\section{Coregistration}

Sato Filtering 

an automatic crack propagation and front location monitoring

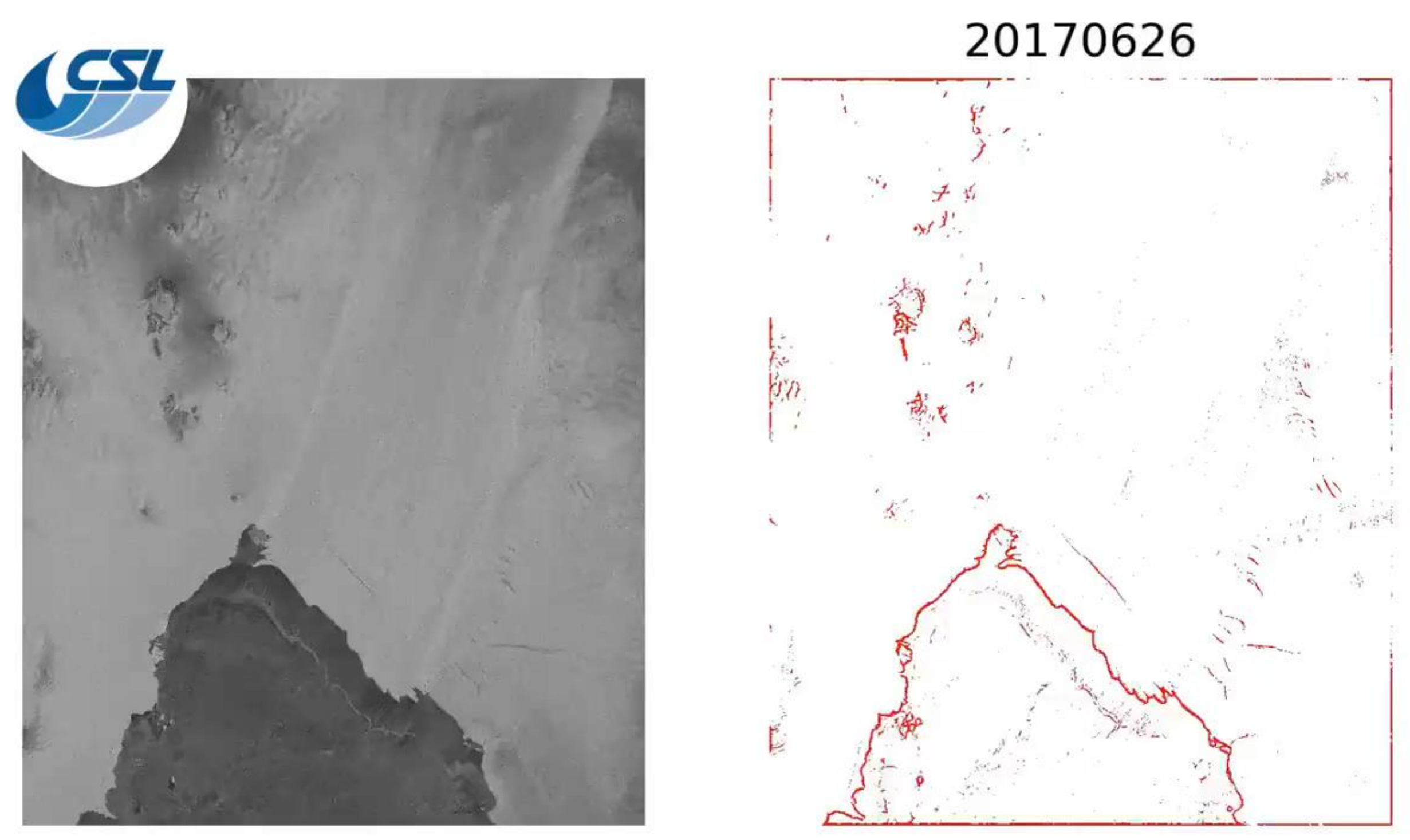


Comparison between June 2017 (blue) and June 2020 (red). We observe that the calving front retreated by overall 20 kilometers

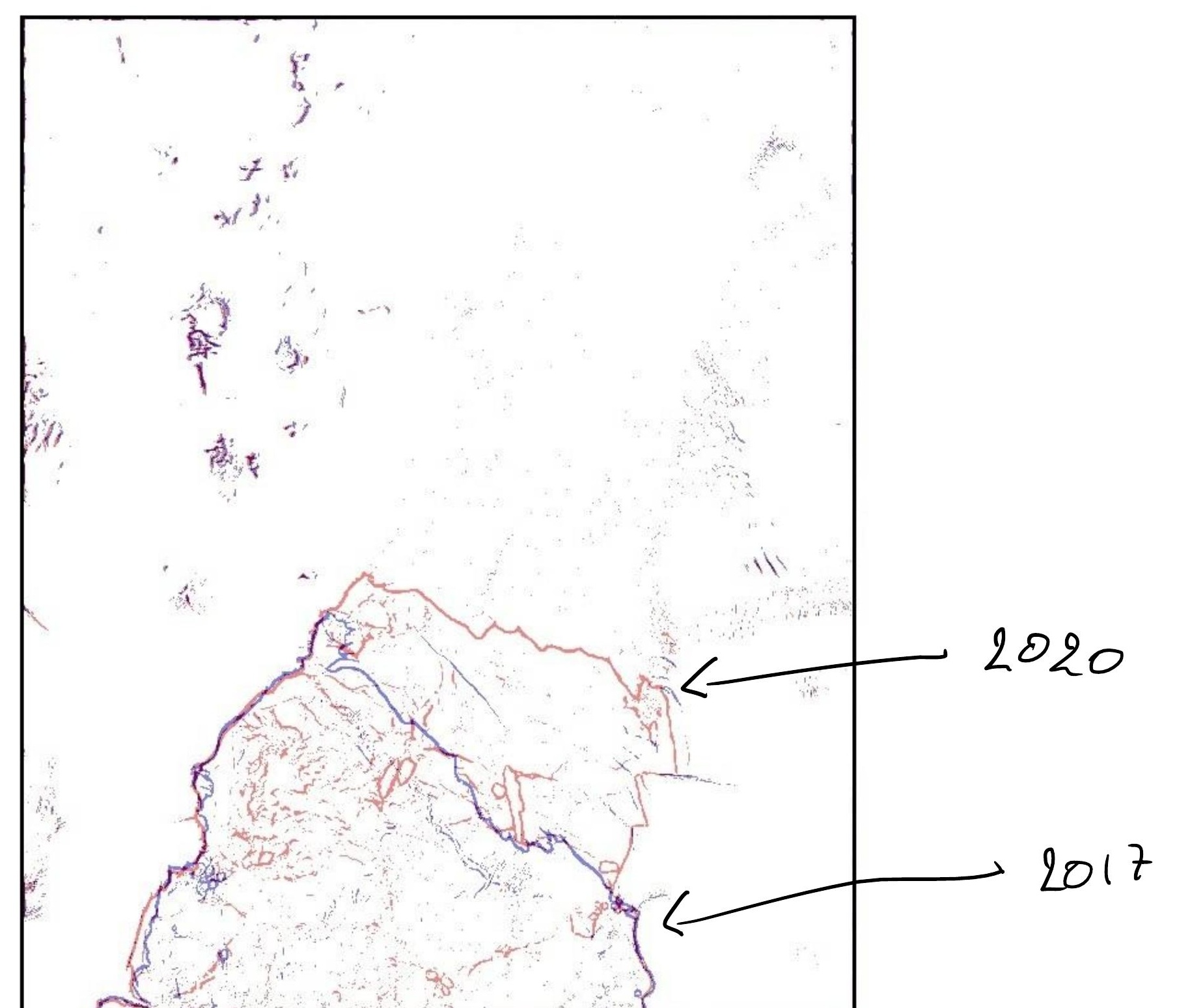


the Brunt Ice Shelf, where break up events can be predicted

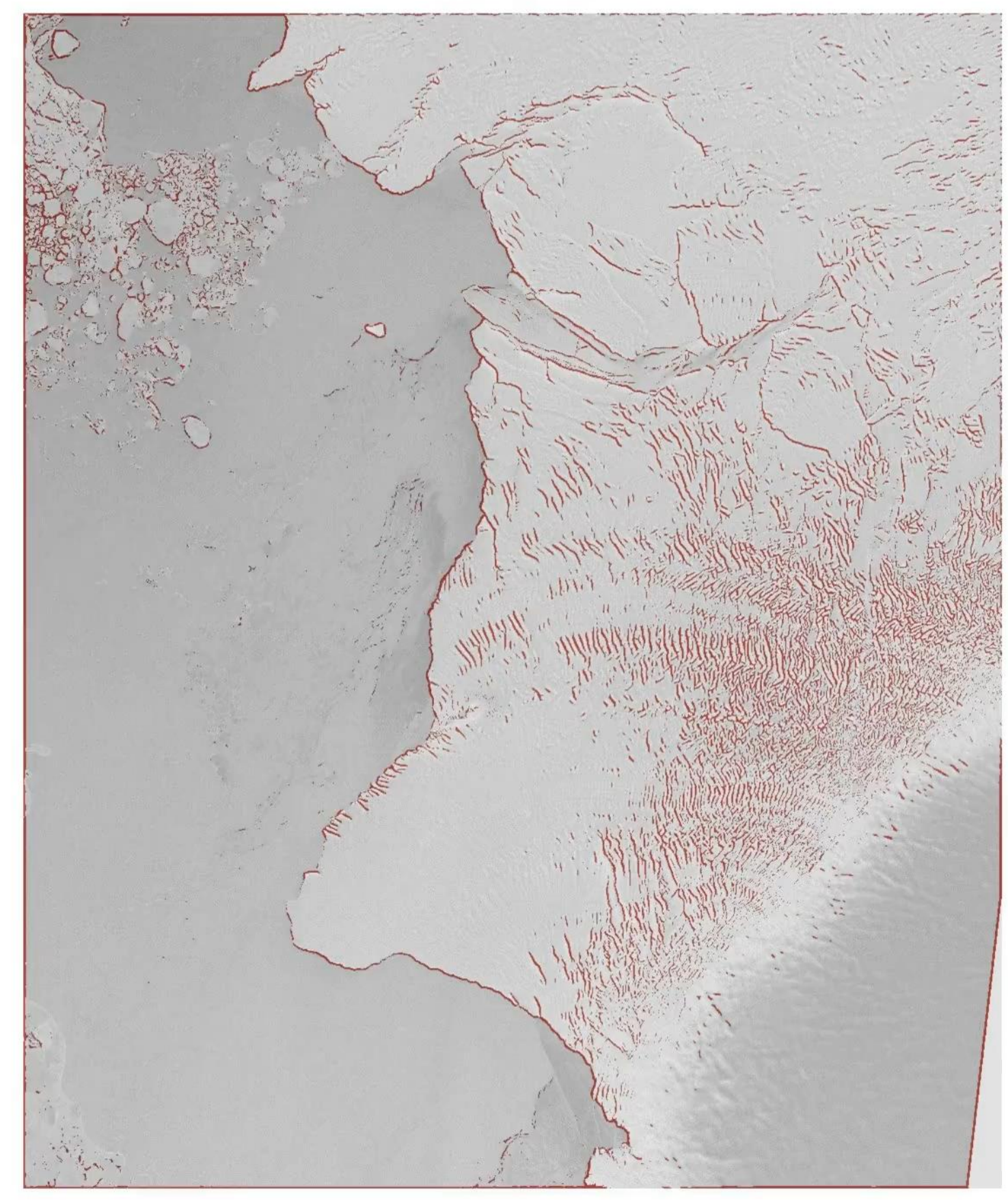


Additional work is needed, and your comments are welcome in this regard. Thanks for attending this session!

Q. Glaude 
Side note: because of speckle noise, we apply the hessian matrix on a gaussian filter signals, using the convolution theorem

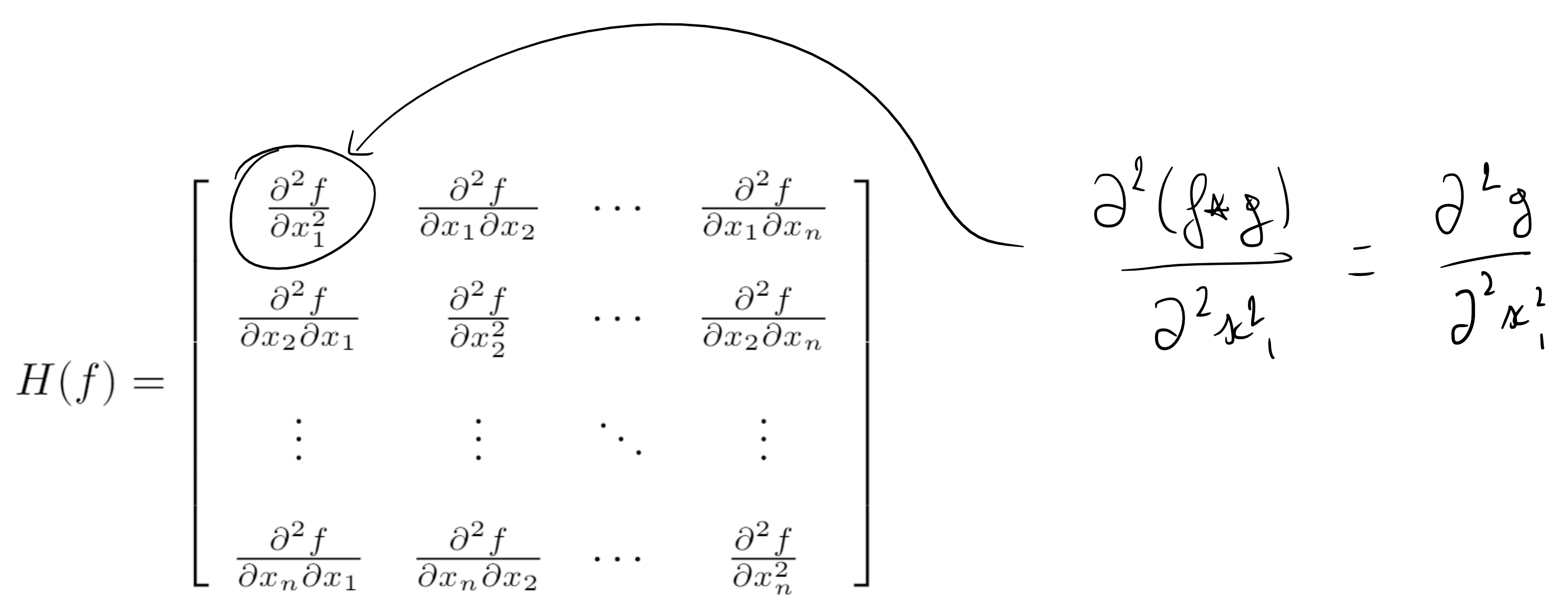

